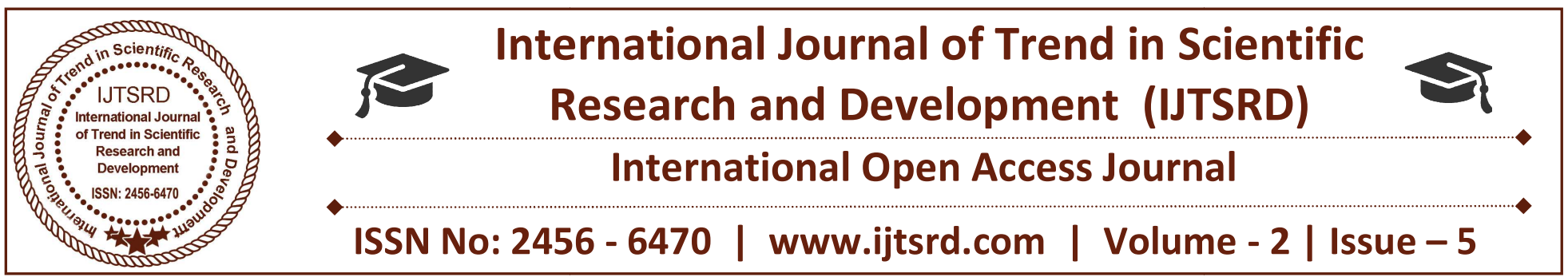

\title{
An Overview of Competition Laws in India
}

\author{
Parmesh. N \\ Student, Sastra Deemed to be University, Thanjavur, Tamil Nadu, India
}

\begin{abstract}
The enactment of the Competition Act 2002 (the Act), the principal legislation governing competition law in India, along with the establishment of the Competition Commission of India (CCI) 1 as its chief enforcement authority, has been one of the biggest game changers in the Indian regulatory space. The Act regulates markets in India with the objective of promoting and sustaining competition and, more importantly, protecting consumer interests. Akin to competition regimes in mature jurisdictions, India's competition law covers within its ambit the regulation of anticompetitive conduct, abuse of dominance and unilateral conduct, and combinations. This article focuses on enforcement of provisions relating to unilateral conduct of enterprises and explores the trends in this area, which are steadily evolving on a case-by-case basis.
\end{abstract}

KEYWORD: Competition, MRTP, market, dominance, Anti-competitive Agreements, Combination

INADEQUACY OF THE MRTP ACT TO DEAL WITH COETANEOUS ISSUES RELATING TO MARKET COMPETITION AND TRENDS OF ABUSE OF DOMINANCE

The earlier law which was in force was the Monopolies and Restrictive Trade Practices Act, 1969 (MRTP).It was the first law that regulated free and unbound trade in India. After changes in the trade policy of the nation and inflow of foreign investors into the economy, there was a need for a better regime of law. It was felt that the MRTP law had become obsolete and lost its sustainability. Therefore, a paradigm shift was made from curbing monopolies to preventing the misuse of dominance of power.[v] Under the MRTP Act, no provision for abuse of dominant position was defined. The bare bones however were laid by restricting anti competitive practices. The MRTP Act did not prescribe a mechanism to deal with cartels, predatory prices, bid rigging, collusion and price fixing, all of which were equally pertinent.

Competition law has been relatively under-developed in India. The need for the Competition Act,2002 was felt because of the inadequacy of the MRTP Act to deal with the contemporaneous issues pertaining to cartels, predatory pricing and abuse of dominant position. The Indian markets are fast evolving and therefore the need for a stringent law to protect the interests of the competitors, buyers and customers is acutely felt. This article analyses the aspect of dominant position in relevant markets and its characteristics features. It also discusses the issue of abuse of dominance in light of recent incidents

\section{RELEVANT PRODUCT MARKET RELEVANT GEOGRAPHIC MARKET \\ Relevant Product Market}

The expression "relevant product market" has been defined under the Act as "market comprising all those products or services which are regarded as interchangeable or substitutable by the consumer, by reason of characteristics of the products or services, their prices and intended use." Relevant product market thus includes all reasonable substitutable products or services of nearby competitors, to which consumers could turn without compromising substantially with their needs. A good example of this would be the market of toothpastes and tooth powder. Even though they are quite different products but acts as a competitive restrain on each other and thus part of same relevant product market. The Act prescribes certain factors and all or any of them can be 
considered by the Commission while defining the relevant product market.

\section{Relevant Geographic Market}

Geographic dimension involves identification of the geographical area within which competition takes place. Relevant geographic markets could be local, national, international or occasionally even global, depending upon the facts in each case. Some factors relevant to geographic dimension are consumption and shipment patterns, transportation costs, perishability and existence of barriers to the shipment of products between adjoining geographic areas. For example, in view of the high transportation costs in cement, the relevant geographical market may be the region close to the manufacturing facility. The Act defines the term "relevant geographic market" to mean a market comprising the area in which the conditions of competition for -(a) Supply of goods or provision of services, or (b) Demand of goods or services are distinctly homogenous, and can be distinguished from the conditions prevailing in the neighbouring areas. The Act also prescribes some factors and any or all of these factors can be considered by the Commission while defining the scope of relevant geographic market, these factors are
A. regulatory trade barriers;
B. local specification requirements;
C. national procurement policies;
D. adequate distribution facilities;
E. transport costs;
F. language;
G. consumer preferences;

H. need for secure or regular supplies or rapid aftersales services.

\section{A. Definition of the term "Enterprise"}

"Enterprise means a person or a department of the Government, who or which is, or has been, engaged in any activity, relating to the production, storage, supply, distribution, acquisition or control of articles or goods, or the provision of services, of any kind, or in investment, or in the business of acquiring, holding, underwriting or dealing with shares, debentures or other securities of any other body corporate, either directly or through one or more of its units or divisions or subsidiaries, whether such unit or division or subsidiary is located at the same place where the enterprise is located or at a different place or at different places, but does not include any activity of the Government relatable to the sovereign functions of the Government including all activities carried on by the departments of the Central Government dealing with atomic energy, currency, defence and space .

\section{B. The definition of Relevant Market varies from place to place.}

In practice, the CCI's definition of the relevant market varies from case to case, based on the differing factual matrix. As such, the CCI has restricted the relevant geographic market to particular suburbs in some cases (such as Belaire Owners' Association v DLF Limited 8 and Mr Om Datt Sharma v M/s Adidas AG \& Ors)9 and has, without any specific differentiation, defined the relevant market on an 'all India basis' in other cases. For instance, in Consumer Guidance Society v Hindustan Coca Cola Beverages Pvt Ltd \& INOX Leisure Private Ltd,10 the CCI held that the relevant geographic market cannot be confined to the closed market inside the premises of multiplexes and defined the relevant market to be the market for multiplexes on an 'all India basis'.

\section{C. "Market share" alone cannot be decisive proof of dominance.}

Under the provisions of the Act, dominance refers to the ability of an enterprise to operate independently of market forces and exploit its position of strength to affect competitors or consumers or the relevant market in its favour. While determining dominance, the CCI considers factors listed under section 19(4) of the Act. Consequently, an enterprise's dominance is a multifaceted assessment and there is no bright line market share test. Reaffirming this view, in $\mathrm{Mr}$ RamakantKini v Dr L H Hiranandani Hospital, Powai, Mumbai, while assessing the dominance of the Hiranandani hospital in the relevant market for provision of maternity services by super speciality and high-end hospitals within a distance of 12 kilometres from the Hiranandani Hospital, the CCI clarified that the market share of an entity is 'only one of the factors that decides whether an enterprise is dominant or not, but that factor alone cannot be decisive proof of dominance'.

Similarly, in In re $\mathrm{M} / \mathrm{s}$ ESYS Information Technologies Pvt Ltd and Intel Corporation (Intel Inc) \& Ors, 19 in addition to the market shares of Intel, the CCI's assessment of Intel's dominance was based on other relevant factors, such as consumer preference owing to the brand name, the existence of strong entry barriers in the relevant market, the significant 
intellectual property rights of Intel and the scale and scope enjoyed by Intel.

\section{Defining Global Market as Relevant Market is inconsistent and incongruous to the provisions of the Act.}

Interestingly, in Maharashtra State Power Generation Limited v Coal India Limited and Ors (Coal India), 11 the CCI noted that defining a global market as the relevant market was contrary to the express provisions of the Act. The CCI reasoned that the explanation to section 4 of the Act indicated that the 'dominant position' is a position of strength enjoyed by an enterprise in the relevant market 'in India'. Accordingly, the contention of the parties to define the relevant geographic market as the global market was held by the CCI as legally untenable. Though the facts of Coal India may have warranted restricting the relevant market to India, by concluding that a worldwide definition of the relevant market would not be permissible in any instance of abuse of dominance, the $\mathrm{CCI}$ has adopted a narrow and restrictive view. In doing so, the CCI has failed to consider products that are not affected by national barriers.

\section{MODUS FOR DETERMINING RELEVANT MARKET}

\section{Demand substitution}

Under the method of demand substitution, a list of products capable of acting as substitutes for the product in question is prepared. Thereafter, the commission tries to find out whether the consumers of the product in question would switch to other alternatives if the relative price of such product is increased by a hypothetical small but permanent amount, generally in range of $5 \%$ to $10 \%$. If the increase in relative price result in product substitution then the entire range of alternatives the consumers have relied upon are included in the relevant market.

\section{Supply substitution}

The method of Supply substitution may also be taken into account when defining the relevant markets in those situations in which its effects are equivalent to those of demand substitution in terms of effectiveness and immediacy. Under this method all those product substitutes are included in the relevant market, suppliers of which are able to switch production to these substitutes and market them in the short term without incurring significant additional costs or risks in response to small and permanent changes in relative prices. However, under this method if producing alternatives would require significant adjustment to existing tangible and intangible assets, additional investments, strategic decisions or time delays, these alternatives will not be included in the relevant market.

\section{Potential competition}

The third source of competitive constraint, potential competition, is not taken into account when defining markets, since the conditions under which potential competition will actually represent an effective competitive constraint depend on the analysis of specific factors and circumstances related to the conditions of entry. If required, this analysis is only carried out at a subsequent stage, in general, once the position of the companies involved in the relevant market has already been ascertained, and when such position gives rise to concerns from a competition point of view.

\section{DELINEATION OF BCCI CASE TO DETERMINE THE RELEVANT MARKET CONCEPT}

Mr. Surinder Singh Barmi, a cricket fan, alleged irregularities against the Board for Control of Cricket in India ("BCCI") in the grant of franchise rights for team ownership, media rights for coverage of the league and award of sponsorship rights, and other contracts related to the organization of the Indian Premier League. BCCI refuted the allegations and reasoned that it is a "not-for-profit" society for the promotion of cricket and its activities and is not an "enterprise" under section 2(h) of the Act. It also cited a decision of the Supreme Court3 which directed the government not to denigrate sports organizations by placing them on par with business organizations and took the stand that sports associations exist primarily to educate sportsmen, promote and popularize the sports. The allegations of team ownership, media and sponsorship rights in separate markets, cannot substitute each other and are not interchangeable. However, it agreed with a monopoly position, but only for a pro-competitive effect.

CCI concluded that BCCI is an enterprise. It relied upon an order of the Director of Income Tax Exemptions, which had withdrawn the exemption granted to BCCI under section 12A of the Income Tax Act. In that order, the tax authority had considered the changes in the status and memorandum of BCCI by an assessment order dated December 28, 2009. It further drew support from the decision of the High 
Court of Delhi4 which declared that the All India Chess Federation is an "enterprise" within the meaning of section 2(h) of the Act. Since revenue is the primary consideration for private professional leagues, CCI identified the relevant market as the "Organization of Private Professional Cricket Leagues/Events in India". Further, dominant position in the market was determined based on BCCI's regulatory role, monopoly status, control over infrastructure, players and entry of other leagues and use of its regulatory powers to foreclose the market for other competitors by giving an undertaking not to support any competing league. All of this was identified as an abuse of dominant position.

With a view to open up venues for young population to play cricket and to find champions by allowing more private professional leagues, CCI directed the BCCI on February 08, 2013 to cease and desist from any practice in the future denying market access to potential competitors and imposed a penalty of $6 \%$ of past three years average annual revenue, i.e. a sum of INR 522,400,000 (about US\$ 7.9 million).

Elucidation of the concepts of "abuse of dominance and Appreciable Adverse effect on Competition" Determination of Abuse of dominance using certain factors and assessment of dominance

While assessing the dominance of an undertaking it is important to consider all the constraints present in the market, which hinders its ability to act independently and affect the relevant market in its favor. The Act lists some factors, all or any of which can be considered by the Commission while inquiring whether an enterprise enjoys a dominant position or not. These factors help the Commission to precisely and accurately assess the dominance of alleged undertaking under the relevant market by providing an objective point of view. These factors are -

A. Market share of the enterprise;

B. Size and resources of the enterprise;

C. Size and importance of the competitors;

D. Economic power of the enterprise including commercial advantages over competitors;

E. Vertical integration of the enterprises or sale or service network of such enterprises;

F. Dependence of consumers on the enterprise;

G. Monopoly or dominant position whether acquired as a result of any statute or by virtue of being a Government company or a public sector undertaking or otherwise;
H. entry barriers including barriers such as regulatory barriers, financial risk, high capital cost of entry, marketing entry barriers, technical entry barriers, economies of scale, the high cost of substitutable goods or service for consumers;

I. Countervailing buying power;

J. Market structure and size of the market;

K. Social obligations and social costs;

L. Relative advantage, by way of the contribution to the economic development, by the enterprise enjoying a dominant position having or likely to have an appreciable adverse effect on competition;

M. Any other factor which the Commission may consider relevant for the inquiry.

\section{Hoffman - La Roche Case -}

- La Roche Case -

In this Hoffman case, the defendants were seller of inter alia Vitamins $\mathrm{C}$ and $\mathrm{E}$. These two products were mainly used for two purposes Bio- nutritive use or additives to food stuff, under which both the products performed different functions and could not substitute each other in respect of function.

Technological use, under which their use as antioxidant and fermentation agent were interchangeable. The defendants contested that due to the technological use Vitamins $\mathrm{C}$ and $\mathrm{E}$ are part of the much larger market comprising of other products suitable for the same and the Commission has exaggerated its share in the said market. The court did not agree and held that each of these groups must be placed in the separate market, one comprising of vitamins for bionutritive use and other vitamins for technological use.

\section{Continental Can Case -}

In this case the court applied the supply side substitution while defining relevant market. In this case the defendants contended that the market for light containers for containers for canned meat products, the market for light containers for canned seafood and the market for metal closures for the food packing industry, other than crown corks are different from each other and must be considered separately. The court rejected their contention and held that all these market formed part of one "light metal container market" and not there different types of market applying the supply side substitution. The court further observed that In order to be regarded as constituting a distinct market, the products in question must be individualized, not only by the mere fact that 
they are used for packing certain products, but by particular characteristics of production which make them specifically suitable for that purpose. Consequently, a dominant position on the market for light metal containers for meat and fish cannot be decisive, as long as it has not been proved that competitors from other sectors of the market for light metal containers are not in a position to enter the market, by simple adaption, with sufficient strength to create serious counter weight.

\section{Hoarding of vegetables and grains}

For example: $\mathrm{X}$ is a businessman and enjoys a dominant position in the food market as he keeps huge stocks of vegetables and most of the retailers get supplies from him, which is the reason for which he enjoys a dominant position. And one day $\mathrm{X}$ purchases about 80 percent of the total produce of onions and then refuses to supply the same to the retailers, as a result the supply of onions in the market has diminished and demand for onion has increased, as onions form the base of Indian cooking. As the demand for onions has increased the price of onion has gone up as well, so when the price of onion increased $X$ sold all of the onions at a premium rate and made a huge profit. This act done by $\mathrm{X}$ is called as abusing of one's dominant position. The consumers in need of onions will buy them at whatever price $X$ will dictate.

\section{Exclusionary Activities}

Exclusionary activities are those in which the dominant entity uses its dominance to restrict entry of competition into the relevant market. For example, in Re ShriShamsherKataria v Seil Honda [12], where there existed agreements between the dominant entities and the Overseas Suppliers of original car parts which prevented the Overseas Suppliers from supplying parts to independent repairers, such agreements were held to be anti-competitive as they restricted entry of new firms.

Exploitative activities, meanwhile, are those where the dominant entity exploits its dominance by imposing discriminatory and/or unjust conditions on other firms or consumers. A case in point would be Pankaj Agarwal, where, in a case pertaining to allotment of apartments, the contracts drafted unilaterally by DLF enabled them to be arbitrary about allotment of super-area, secretative about information relevant to the purchaser, like, the number of apartments on a floor, and to cancel allotments and forfeit booking amounts. The Commission held the contracts to be exploitative against buyers, and thus, abusive.

\section{"Issue of per se violations"}

Statutorily, an abuse of dominance is required to be treated as a per se violation, and the CCI has followed this approach in several cases, including in the case of Board of Control for Cricket in India (BCCI) $\mathrm{v}$ Competition Commission of India and Anr (BCCI Case) 21 wherein the CCI held that the BCCI had allegedly denied access to the market for organisation of private professional cricket in India by virtue of a clause in the media rights agreement to not organise, sanction or support any other professional domestic Indian Twenty-20 league in India, and it imposed a penalty on the BCCI. In contrast, in DhanrajPillai v Hockey India,22 the CCI brought in the effects test and went so far as to state that the restrictive conditions imposed on hockey players were 'intrinsic and proportionate' to Hockey India's objectives and therefore did not amount to an abuse of dominance. Subsequently, disregarding its own precedent, in Faridabad Industries Association v M/s Adani Gas Limited,23 despite Adani Gas Limited's (AGL) good conduct by benefiting consumers and the ostensible clauses not being enforced, the CCI imposed a penalty on AGL.

This demonstrates the varying position that the CCI has adopted and the urgent need to develop a high degree of consistency and predictability in its assessment of abuse of dominance cases.

\section{OBJECTIVE JUSTIFICATION AND EFFICIENCIES- TO MEET THE COMPETITION IN THE MARKET}

The Act covers within its ambit both exclusionary as well as exploitative abuses and provides a list of prohibited conduct by dominant enterprises, including imposition of unfair or discriminatory conditions on price in purchase or sale (including predatory pricing), limiting or restricting the production of goods, denial of market access, and leveraging market position in one relevant market to enter into another relevant market, shall amount to abuse of dominance. Further, except for the limited defence of 'meeting competition' in relation to imposition of unfair and discriminatory prices or conditions, the Act does not provide for any other exemption to an abuse of dominance violation. This is in stark contrast to the European Union, where the 'objective justification' or 
'efficiencies' defence has often been held to be a valid defence. However, the CCI has recently begun to consider business and commercial justifications, on a case-by-case basis, as a potential defence in such cases.

\section{PENALTIES AND SANCTIONS \\ Mitigating factors for the determination of the penalty}

The CCI has the power to impose the highest economic penalties in India among all regulators. In the case of contravention of Section 4 of the Act, the CCI is empowered to levy a penalty of up to 10 per cent of the average turnover of the enterprise for the preceding three financial years 24 or direct the division of a dominant enterprise. However, as there are no guidelines issued by the $\mathrm{CCI}$ in relation to the determination of penalties, the CCI currently has absolute discretion in relation to the imposition of such penalties. Additionally, in most cases, there is an absence of coherent justification for the penalties imposed. For instance, in the Auto Parts case, all the OEMs were fined the same percentage quantum, despite differences in market conduct that ought to have been considered as a mitigating factor.

The CCI has, in very few instances, taken into account factors that may be regarded as mitigating factors for the determination of the penalty. For instance, in a recent case, the CCI has considered the steps taken by the opposite parties in the interim period (between the informant filing information alleging an abuse of dominance and the CCI's order), which may have an effect of reducing competition law concerns, while determining the penalty to be imposed.

In the case of Indian Exhibition Industry Association v Ministry of Commerce \& Industry \& Another, the Indian Exhibition Industry Association filed an information against the Ministry of Commerce and Industry and the Indian Trade Promotion Organization (ITPO), alleging the contravention of the provisions of section 4 of the Act based on the time gap restriction imposed by ITPO between two exhibitions or fairs. In 2006, the ITPO had reformulated certain guidelines imposing a 'time gap restriction' of 15 days between two events having similar product profiles and coverage for events that were not conducted by ITPO. However, in case of ITPO fairs, the time gap was 90 days before the start or 45 days after the close of an ITPO event. Further, in 2007, the concerned guidelines were reassessed and the time gap of 15 days was maintained. However, in case of ITPO and third-party fairs having similar product profiles, the time gap was 90 days before the ITPO's event and 45 days after it. The CCI held that ITPO was 'playing a dual role as a regulator as well as the organiser of exhibitions' and, as such, considered the acts of ITPO to be an abuse of its dominant position. The penalty imposed by the CCI on the ITPO was limited to 67.5 million rupees (around 2 per cent of the average of the turnover for the preceding three years). The removal of discriminatory features and the differences in time gap restrictions by an amendment in 2013 was considered by the CCI as a mitigating factor.

\section{PATH BREAKING JUDGMENTS DELIVERED BY THE COMPETITION COMMISSION OF INDIA \\ $\mathrm{M} / \mathrm{s}$ Google Inc and Google India Private Limited Case}

It may also be noted that the CCI imposed a penalty of 10 million rupees on (collectively, Google) 31 for failing to comply with the directions of the director general seeking certain information with respect to the ongoing abuse of dominance investigation against Google. The CCI observed that no cause was shown by Google for non-compliance with the directions given by the director general, sending a strong message that the investigation process cannot be unnecessarily delayed. It was further noted that despite liberal indulgence shown by the director general in granting successive extensions, Google had engaged in delaying tactics to prolong the investigations. Accordingly, the CCI imposed the maximum penalty envisaged under section 43 of the Act (10 million rupees) and ordered Google to furnish all the information required by the director general within a period of 10 days. The CCI further clarified that in case of any non-compliance with the directions of the director general in the future, each instance of non-compliance would be taken separately as an aggravating factor for the imposition of a penalty.

In the BCCI Case, for the first time ever, COMPAT set aside the order of the CCI in entirety, which had held that the BCCI had abused its dominance in the market for 'organisation of private professional leagues/events in India' on account of violation of the principles of natural justice. COMPAT ordered a refund of the penalty amount and remanded the case to the CCI for fresh investigation. 
NSE Case - MCX Stock Exchange v NSE, Case 13 of 2009,

In this case the Commission acting on a complaint by the MCX Stock Exchange (hereinafter referred to MCX-SX), ordered an investigation into the alleged misuse of dominant position by the National Stock Exchange(hereinafter referred to as NSE), the country's largest bourse. The investigation, carried out by a director general (DG) of CCI, has found that NSE violated Section 4(2)(a)( ii), and Section 4(2)( e) read with 4(1) of the Act.

The MCX-SX had alleged that NSE was indulging in unfair practices or predatory pricing by waiving the transaction fee on currency derivatives. The MCX-SX contended that NSE has waived its transaction fee on currency derivatives and instead, charges a fee of Rs 2/ Lakh on the turnover in its derivatives segment. Due to NSE's waiver MCX-SX is also unable to levy such a fee leading to significant losses and new investors are not likely to be attracted in the market of currency derivatives.

NSE, in its reply to the commission, contended that the intention to eliminate competition is an important ingredient of predatory pricing, and the fee waiver in the new currency derivative segment, referred to in the allegation, is in the nature of introductory pricing with no intention to eliminate competition.

The commission in its decision observed that "based on evidence and after considering the arguments of both information provider (MCX-SX) and NSE, it is proved beyond reasonable doubt that NSE has the design of eliminating competition, the commission said in its concluding remarks. The NSE had used every tactics to harm competition by using its dominant position in the relevant market (stock exchange space) and has also protected its dominant position in CD (currency derivatives) segment by using its monopoly revenues from other segments."

\section{Shri Shamsher Kataria v Honda Siel Cars India Ltd \& Ors}

In Shri Shamsher Kataria v Honda Siel Cars India Ltd $\&$ Ors (Auto Parts), 15 the CCI undertook a detailed analysis while delineating the relevant market. In this case, the information was filed against various automobile manufacturing companies or original equipment manufacturers (OEMs) on the basis that the OEMs were involved in activities leading to competition law concerns in India by restricting the availability of genuine spare parts of auto-mobiles manufactured by them in the open market. It was also alleged that the car manufacturing companies controlled the operations of various authorised workshops and service stations that were in the business of selling automobile spare parts besides rendering after sales automobile maintenance services. The technological information, diagnostic tools and software programmes required to maintain, service and repair the technologically advanced automobiles manufactured by each OEM were unavailable in the open market. Consequently, the repair, maintenance and servicing of such automobiles could only be carried out at the workshops or service stations of the authorised dealers of the OEMs.

The CCI noted that the consumers in the primary market (ie, the market for the manufacture and sale of cars) did not, or could not, undertake a whole-life cost analysis at the time of purchase of the automobile and, accordingly, the CCI did not accept the 'unified systems market definition submitted by the OEMs and concluded that the automobile primary market for automobiles and the secondary market (or 'aftermarket') for spare parts, diagnostic tools and repair services did not constitute a unified systems market.16

Noting that each OEM had a 100 per cent market share in the aftermarket for its brand of cars, the CCI held each OEM to be a dominant entity in such. As such, the CCI considered each individual separate brand of automobiles as a separate relevant market, instead of considering the broader relevant market of the aftermarkets for the entire automobile industry. Based on this analysis, the CCI concluded that the OEMs had abused their dominant position in their respective aftermarkets by, inter alia, restricting the supply of spare parts, repair manuals and diagnostic tools to independent repairers. The order of the CCI was, in most parts, affirmed in appeal by the Competition Appellate Tribunal (COMPAT) in Toyota Kirloskar Motor Private Limited and Ors v Competition Commission of India and Ors and Nissan Motor India Private Limited $\mathrm{v}$ Competition Commission of India and Ors (COMPAT Auto Parts).

\section{CONCLUSION:}

The shift from the previous competition regime to the current one is from structure to conduct and from rule of law to rule of reason. To enable this task, robust powers are granted to $\mathrm{CCI}$ in terms of enhanced 
authority, penalizing provisions, and a dedicated appellate authority. A competition law expert can test all haphazard ways of commercial life to iron out distortions and market strategies that are not desirable for healthy competition. CCI is a new paradigm. No wonder the cartels in the cement industry and bid rigging in government procurements by liquid petroleum gas cylinder manufacturers and explosive manufacturers had not been brought to book till now.

Regulatory bodies are institutionalized for independent management of the sector. The Supreme Court has recently enunciated the important role of a regulator while considering the powers/competence of the Telecom Regulatory Authority of India. However, several high courts are failing to appreciate the role of regulators, particularly CCI, which was set up in 2009. Its jurisdiction is still questioned and high courts are brisk installing investigations initiated by them. The question then arises-do courts have a socalled mental picture of how the markets are watched by competition authorities in other jurisdictions? The success or failure of CCI will have no small significance for the Indian economy, but failure cannot be afforded. 